\title{
Research on World Food Production Efficiency and Environmental Sustainability Based on Entropy-DEA Model
}

\author{
Min Zhang $\mathbb{D}^{1},{ }^{1}$ Wen-Kai Cui $\mathbb{D}^{2},{ }^{2}$ Yu-Jing Zhang $\mathbb{D}^{2}$, and Yun-Hua Xu $\mathbb{D}^{3}$ \\ ${ }^{1}$ School of Statistics and Applied Mathematics, Anhui University of Finance and Economics, Bengbu 233030, China \\ ${ }^{2}$ Institute of Finance, Anhui University of Finance and Economics, Bengbu 233030, China \\ ${ }^{3}$ School of Business Administration, Anhui University of Finance and Economics, Bengbu 233030, China
}

Correspondence should be addressed to Yun-Hua Xu; yhxu2005@163.com

Received 15 May 2021; Accepted 27 June 2021; Published 7 July 2021

Academic Editor: Shaohui Wang

Copyright $\odot 2021$ Min Zhang et al. This is an open access article distributed under the Creative Commons Attribution License, which permits unrestricted use, distribution, and reproduction in any medium, provided the original work is properly cited.

\begin{abstract}
At present, the contradiction between the high efficiency of the world's food production and environmental pollution is becoming increasingly prominent. In order to study the related issues of the world's food production efficiency and sustainability, this paper uses the method of entropy weight to extract 5 indicators as the environmental pollution assessment model from the environmental pollution of agricultural production, scores 10 major agricultural production countries in the world, and obtains the environmental pollution index. Subsequently, the DEA model was established for these countries, the environmental pollution index was included into the production efficiency system as an unexpected output, the Malmquist index was established to describe the changes in agricultural production efficiency from 2010 to 2018, and the cluster analysis was carried out for it. Subsequently, the OSL and Tobit models were used for regression of the influencing factors. In addition, the comprehensive evaluation model of efficiency and sustainability was established by controlling the amount of fertilizer used, which was applied in different countries.
\end{abstract}

\section{Introduction}

With the continuous development of the current world economy, food production is becoming more and more efficient, and the food produced is enough to feed every individual in the world. However, 821 million people still suffer from the food hunger crisis worldwide $[1,2]$. The current food system is well illustrated by the increasing global environmental disruption to produce adequate food, which includes a series of consumption such as greenhouse gas emissions, deforestation, and agricultural irrigation [3-7]. In studying food production systems, it is of great importance to rationally evaluate and improve the current global food system, on the one hand, considering the advantages of high efficiency for food production under the current model and, on the other hand, focusing on the environmental sustainability issues due to high efficiency $[8,9]$.

Due to the differences of geographical and climatic factors and customs preferences, different countries have different focus of agricultural production, and there are obvious differences in environmental factors such as planting, animal husbandry, and fishery $[10,11]$. The LCA method is often used to evaluate the environmental pollution of crops in the whole life cycle $[12,13]$. However, agricultural production and consumption are characterized by a large time span, and this activity is constantly changing, so it is difficult to measure. In the aspect of objective comprehensive evaluation, the entropy weight method can better measure the existing statistical data and get better results [14-16]. In the aspect of agricultural production efficiency, the DEA method is often used to measure the efficiency and productivity between similar decision-making units. By adding various constraints on the basis of the DEA method, more production efficiency models can be obtained to solve efficiency problems in various situations [17-19].

In this review, we first provide an explanation for the production efficiency and sustainability of the current global food system based on the use of the entropy weight method 
to establish an evaluation system for environmental pollution and the introduction of the EPI as a measure, followed by the use of the DEA model to establish a model for the evaluation of the efficiency of global food production and the inclusion of the EPI as an undesired output into production system when the model of SBM hyper efficiency is established. After that, two methods, OLS and Tobit, were used to analyze the factors affecting the efficiency of global food production by using fertilizers as hubs to connect the environmental pollution assessment model with the food production efficiency model, respectively, and then, agricultural efficiency and sustainability in representative regions were summarized, and the model was applied to different developing and developed countries, thus fully illustrating model stability and fitness. Finally, corresponding improvement measures and policy recommendations are proposed, which will be highly instructive for agricultural sustainable development.

\section{Data Sources and Basic Assumptions}

The data in this paper come from Question E of the 2021 American College Students Mathematical Modeling Competition and the statistics of the World Bank. In order to solve the problem, we make assumptions as follows: (i) assume that the data consulted are true and reliable; (ii) assume there is no emergency that affects the agricultural system; (iii) assume there is no geographic influence in agricultural production; and (iv) we only consider the world's major food producing countries as the evaluation object and ignore the small food producing countries.

\section{Environmental Pollution Assessment Model}

The current world agricultural system has successfully fed more than 70 billion people, but it has paid a huge price for the deterioration of the world's environment. It is pointed out that $25 \%-33 \%$ of greenhouse gases come from agricultural activities such as fertilization, cultivation, production, and incineration in Figure 1 which reflects the global trend of changes in agricultural $\mathrm{CO}_{2}$ emissions and grain production in recent years [20]. Although the growth rate of agricultural $\mathrm{CO}_{2}$ emissions in recent years has decreased, the total amount is still at a high level. According to relevant research, the atmospheric $\mathrm{CO}_{2}$ concentration will reach more than $450 \mathrm{ppm}$ in 2050 . The rise of sea level and abnormal temperature caused by greenhouse gases has further caused serious damage to human agricultural production [21].

With the increasingly modern cities and the growth of population, the world's fresh water demand is also rising gradually. At the same time, the consumption of fresh water resources by agricultural activities cannot be ignored. Irrigation water is more than any other human activities. The regeneration ability of water resources is closely related to the stability of the food system. The current global regional food production system is in an unbalanced state. In addition to the production of necessary crops (such as rice, wheat, and cotton), it also invests a large amount of water resources into the production of inefficient food (such as avocado in Mexico). Even with the same kind of crops, the water productivity in developed countries will be much higher than that in developing countries. Therefore, choosing crops with high water productivity can not only relieve the pressure of water resources but also produce more food for food shortage areas $[22,23]$.

In order to meet the growing demand for planting, private growers and small-scale growers, in order to seize the agricultural market, burned forests on a large scale to quickly obtain arable land. In Indonesia, for example, before burning, people drain the swamp through canals and then cut down the trees to facilitate subsequent burning. When the forest is burned, the burning vegetation and roots ignite the coal buried underground, which releases a large amount of carbon dioxide [24]. This behavior has led to a significant decline in biodiversity and increased the risk of alien species invasion. And the reduction of the original forest also makes the adverse environmental phenomenon occur frequently.

Fertilizer is the most important part of agricultural production. For a long time, it has become a common phenomenon that the amount of fertilizer is large and the utilization rate is low. This low efficiency and high consumption mode of fertilizer application not only increases the cost of agricultural production but also causes extremely bad environmental pollution. It also increases the content of nitrogen in the soil. With the surface runoff polluting the surface water and underground water, the pollution of nitrates will be expanded, and the human cells may become cancer.

In summary, the current agricultural production pays attention to high efficiency while ignoring the low sustainability risk brought by it. This production mode is based on the future of the global environment as the overdraft cost, so it is particularly important to make an objective assessment of global environmental pollution.

3.1. Environmental Pollution Index. In this paper, an objective weighting method, i.e., the entropy weight method, is adopted to give weight to each index, respectively, according to the degree of variation of each index, so as to obtain a comprehensive index of agricultural environmental pollution.

First of all, the agricultural irrigation area, $\mathrm{CO}_{2}$ emission, deforestation area, and fertilizer use amount of each country are standardized in four indicators:

$$
\begin{aligned}
X_{i j} & =\frac{\alpha_{i j}-\min \left(\alpha_{i j}\right)}{\max \left(\alpha_{i j}\right)-\min \left(\alpha_{i j}\right)}+1, \\
p_{i j} & =\frac{x_{i j}}{\sum_{i=1}^{n} x_{i j}} .
\end{aligned}
$$
follows:
The normalized matrix $P$ of the original matrix is as 


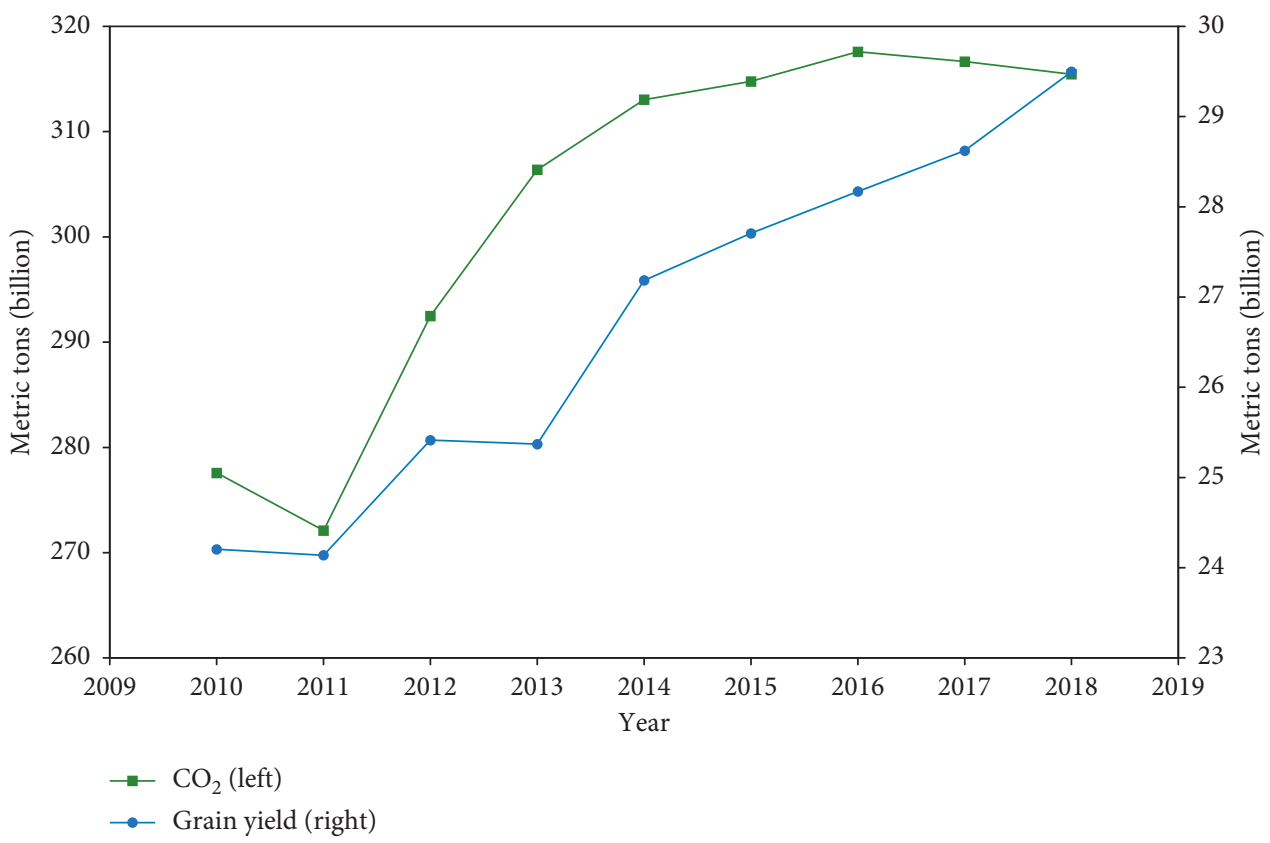

FIgURE 1: $\mathrm{CO}_{2}$ emissions and grain production.

$$
\left(P_{i j}\right)_{m \times n}=\left[\begin{array}{cccc}
P_{11} & P_{12} & \cdots & P_{1 n} \\
P_{21} & P_{22} & \cdots & P_{2 n} \\
\cdots & \cdots & \cdots & \cdots \\
P_{m 1} & P_{m 2} & \cdots & P_{m n}
\end{array}\right] .
$$

Then, we calculate the entropy of each indicator according to the formula as follows:

$$
e_{j}=-k \sum_{i=1}^{n} p_{i j} \ln \left(p_{i j}\right), \quad k=\frac{1}{\ln n} .
$$

We calculate the degree of difference (information utility value) of each indicator and set the difference coefficient as $g_{j}$ which is given as follows:

$$
g_{j}=1-e_{j} .
$$

The weight of each indicator is as follows:

$$
w_{j}=\frac{g_{j}}{\sum_{j=1}^{n} g_{j}} .
$$

Therefore, the comprehensive score of each country can be obtained as follows:

$$
s_{i}=\sum_{j=1}^{m} w_{j} \times p_{i j} .
$$

Because the value of $s_{i}$ is small and not easy to be directly observed, the following method is used to project it into the $[0,100]$ interval to construct the EPI (environmental pollution index) as follows:

$$
\mathrm{EPI}=\frac{s_{i}-\operatorname{Min}\left(s_{i}\right)}{\operatorname{Max}\left(s_{i}\right)-\operatorname{Min}\left(s_{i}\right)} \times 100 .
$$

3.2. Results Analysis. According to the above steps, calculate the collected data and use MATLAB to calculate and obtain the index of the entropy and weight, for the future comprehensive score calculation. The results are shown in Table 1.

After determining the weight and the amount of information, the final comprehensive score of each country's environmental pollution level is obtained, which we call environmental pollution index (EPI), as shown in Table 2.

We use histogram and radar chart to show the score results; in the histogram of Figure 2, the higher the area, the higher the environmental pollution index and the more serious the agricultural pollution.

\section{Grain Production Efficiency Model}

4.1. DEA Model of SBM Super Efficiency. The DEA model is a special tool based on linear programming to evaluate the relative effectiveness of work performance of the same type of organizations. It can effectively eliminate the interference of external environment and random errors on efficiency calculation and can evaluate the world food production efficiency well. However, the pure DEA model can only take the expected output efficiency as the output index and cannot take the unexpected pollutants in the agricultural production process into account in the model [25-27]. Therefore, this paper will use the traditional DEA model based on the use of the SBM super efficiency model so that the DEA method can take into account the unexpected output in the calculation and can reduce the unexpected output from $b_{1}$ to $b_{2}$ and increase the expected output from $g_{1}$ to $g_{2}$ by reducing the input of the decision-making unit, as shown in Figure 3. 
TABLE 1: Weight and entropy.

\begin{tabular}{lcc}
\hline Indicators & Weight & Entropy \\
\hline Agricultural irrigation & 0.1309 & 0.8346 \\
$\mathrm{CO}_{2}$ emissions & 0.1748 & 0.7793 \\
Deforestation & 0.3002 & 0.6208 \\
Fertilizer consumption & 0.3942 & 0.5021 \\
\hline
\end{tabular}

TABLE 2: Score and ranking.

\begin{tabular}{lccccccccccc}
\hline Rank & 1 & 2 & 3 & 4 & 5 & 6 & 7 & 8 & 9 & 10 \\
\hline Country & IND & CHN & VNM & DEU & FRA & USA & BRA & CAN & RUS & ARG \\
EPI & 100 & 61 & 43 & 30 & 26 & 17 & 7 & 4 & 1 & 0 \\
\hline
\end{tabular}

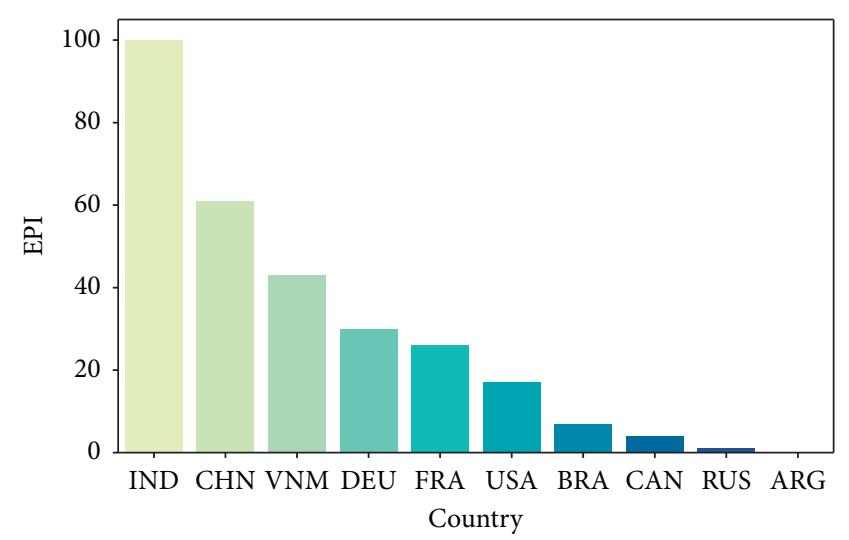

FIGURE 2: EPI histogram.

Assuming that a system has $n$ decision-making units, $m$ inputs, and $s$ outputs, the input and output indicator vectors of the $j$ DMU are as follows:

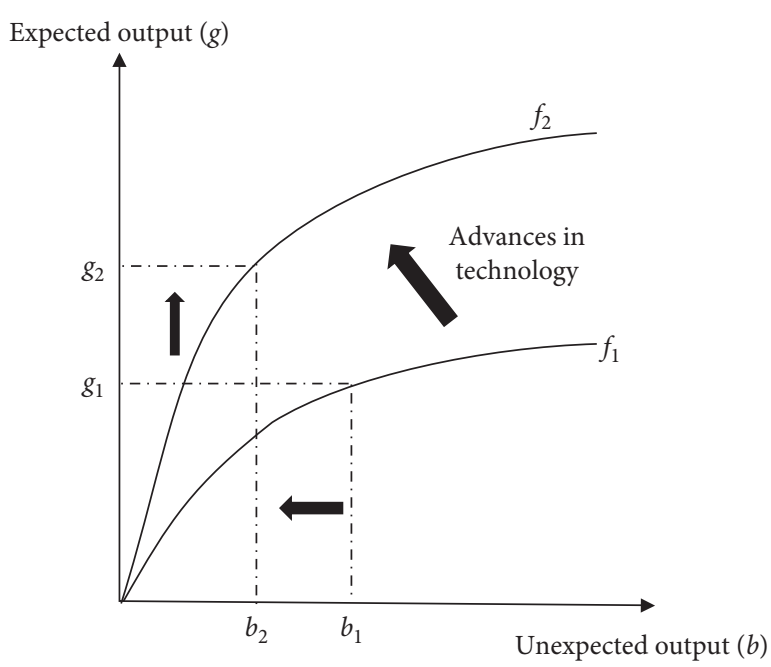

FIGURE 3: DEA method.

$$
X_{j}=\left(x_{1 j}, x_{2 j}, \ldots, x_{m j}\right)^{T}>0, Y_{j}=\left(y_{1 j}, y_{2 j}, \ldots, y_{s j}\right)^{T}>0, \quad j=1,2, \ldots, n
$$

where $X_{i j}(i=1,2, \ldots, m)$ is the $i$ th input variable of the $j$ th DMU and $Y_{i j}(j=1,2, \ldots, s)$ is the $r$ th output variable of the $j$ th DMU. The VRS input-orientated DEA model is as follows:

$$
\begin{cases}\min & \rho_{S E}=1+\frac{(1 / m) \sum_{i=1}^{m} s_{i}^{-}}{x_{i k}} \\ \text { s.t. } & \sum_{j=1, j \neq k}^{n} x_{i j} \lambda_{j}-s_{i}^{-} \leq x_{i k} \\ & \sum_{j=1, j \neq k}^{n} y_{r j} \lambda_{j} \geq y_{r k},\end{cases}
$$

where $\lambda \geq 0, s^{-} \geq 0, s^{+} \geq 0 ; \quad i=1,2, \ldots, m ; \quad r=1,2, \ldots, q$; $j=1,2, \ldots, n(j \neq k) ; \rho_{S E}$ represents the efficiency value of the decision-making unit under the SBM super efficiency model; $x_{i j}$ represents the total amount of input element $i$ in country $j ; y_{r j}$ represents the total amount of type $r$ output in country $j ; s^{+}$and $s^{-}$represent the relaxed variables of input and output vectors; and $k$ represents the country on the effective production boundary.

Environmental efficiency is divided into natural disposable environmental efficiency and management disposable environmental efficiency. Natural disposability refers to reducing the corresponding unexpected output by reducing the input of the system; management disposability, contrary to natural disposability, refers to increasing the expected output of the system and reducing the unexpected output of the system by continuously improving the technical level and increasing the input of the system.

In order to describe the change of agricultural production efficiency over time, this paper uses data from 
different countries during 2010-2018 to construct the Malmquist production efficiency index [28] as follows:

$$
M^{t}=\frac{D^{t}\left(x^{t+1}, y^{t+1}\right)}{D^{t}\left(x^{t}, y^{t}\right)} .
$$

The efficiency change index can be further divided into pure technical efficiency change index and scale efficiency change index:

$$
\begin{aligned}
M\left(x^{t}, y^{t}, x^{t+1}, y^{t+1}\right) & =\left[\frac{D^{t}\left(x^{t+1}, y^{t+1}\right)}{D^{t}\left(x^{t}, y^{t}\right)} \times \frac{D^{t+1}\left(x^{t+1}, y^{t+1}\right)}{D^{t+1}\left(x^{t}, y^{t}\right)}\right]^{1 / 2} \\
& =\left[\frac{D_{c}^{t}\left(x^{t+1}, y^{t+1}\right)}{D_{c}^{t+1}\left(x^{t+1}, y^{t+1}\right)} \times \frac{D_{c}^{t}\left(x^{t}, y^{t}\right)}{D_{c}^{t+1}\left(x^{t}, y^{t}\right)}\right]^{1 / 2} \times \frac{D_{c}^{t+1}\left(x^{t+1}, y^{t+1}\right)}{D_{c}^{t}\left(x^{t}, y^{t}\right)} \\
& =\mathrm{TC}(\mathrm{CRS}) \times \mathrm{EC}(\mathrm{CRS}) \\
& =\mathrm{TC}(\mathrm{CRS}) \times \mathrm{PTEC}(\mathrm{VRS}) \times \mathrm{SEC}(\mathrm{VRS}, \mathrm{CRS}),
\end{aligned}
$$

where

$$
\begin{aligned}
\operatorname{PTEC}(\mathrm{VRS}) & =\frac{D_{v}^{t}\left(x^{t+1}, y^{t+1}\right)}{D_{v}^{t+1}\left(x^{t}, y^{t}\right)}, \\
\operatorname{SEC}(\mathrm{VRS}, \mathrm{CRS}) & =\frac{D_{v}^{t}\left(x^{t}, y^{t}\right)}{D_{c}^{t}\left(x^{t}, y^{t}\right)} \times \frac{D_{c}^{t+1}\left(x^{t+1}, y^{t+1}\right)}{D_{v}^{t+1}\left(x^{t+1}, y^{t+1}\right)} .
\end{aligned}
$$

4.2. Index Selection and Data Processing. In order to study the efficiency of the global food production system, we selected the top 10 countries in the global agricultural production scale in the past few years, namely: China, USA, India, Brazil, Russia, France, Canada, Vietnam, Germany, and Argentina. In this paper, each country is regarded as a decision-making unit (DMU). Therefore, there are a total of 10 DMUs. On the basis of reference to relevant research, we determined the indicators as shown in Table 3.

Output Indicators. The output indicators include expected output and unexpected output. The expected output is agricultural GDP, and the unexpected output is $\mathrm{CO}_{2}$ emission.

Input Indicators. As the DEA model selected in this paper includes unexpected output indicators, not only labor force, agricultural arable land area, and agricultural irrigation area are selected for input indicators but also some indicators that will generate unexpected output but play a key role in food production, including agricultural machinery and fertilizer consumption.

4.3. Results Analysis. The analysis results with DEAP2.1 software are shown in Table 4. Without considering environmental factors and random factors, the average value of agricultural comprehensive technical efficiency, the average value of pure technical efficiency, and the average value of scale efficiency of various countries in 2018 were 0.368 ,
0.769 , and 0.452 , respectively. The maximum comprehensive technical efficiency is 1.000 (China and the United States), and there is room for improvement in other countries in all aspects; the minimum comprehensive technical efficiency is 0.059 (France).

By calculating the Malmquist average index from 2010 to 2018, it can be seen from Table 5 that the development of Vietnam started later, so the development speed in recent years is faster. The EFFCH (technical efficiency), scale efficiency (SECH), and total factor productivity (TFPCH) of the Malmquist average index are the highest, while there is still room for improvement in terms of technological progress. As an old agricultural exporter, Canada has the highest TECHCH and France has the highest PECH.

The Malmquist index from 2010 to 2018 was cluster analyzed by Python, and the corresponding spectrum cluster graph is obtained as shown in Figure 4. The cluster results of agricultural production efficiency of various countries in 9 years can be divided into 3 categories: Canada, Germany, and Russia in the first category; Brazil, China, Vietnam, India, and the United States in the second category; and the other 2 countries belong to the third category and are divided into Argentina and France, respectively.

\section{Regression Analysis of Factors Affecting Production Efficiency}

In order to find the influencing factors of production efficiency, this paper chooses to establish a regression model [29]. Because the minimum value of efficiency value is 0 and the result of the super efficiency model makes the efficiency value not limited to 1 , there is no limitation in the selection of the regression model. In this paper, OLS and Tobit models are selected for analysis.

5.1. OLS Model. The five input factors of the DEA model are taken as independent variables, namely, Labor $\left(X_{1}\right)$, Agricultural Land $\left(X_{2}\right)$, Agricultural Irrigation $\left(X_{3}\right)$, Fertilizer 
TABLE 3: Indicator selection.

\begin{tabular}{lcc}
\hline Input indicators & Output indicators \\
\hline Labor (million) & & Unexpected output \\
Agricultural land (percent of land area) & Grain yield (billions of tons) & Environmental pollution index \\
$\begin{array}{l}\text { Agricultural irrigation (percent of total agricultural land) } \\
\text { Fertilizer consumption (kilograms per hectare of arable land) }\end{array}$ & \\
Agricultural machinery (tractors per 100 Sq. km of arable land) & \\
\hline
\end{tabular}

Consumption $\left(X_{4}\right)$, and Agricultural Machinery $\left(X_{5}\right)$. The ecological efficiency value $(Y)$ calculated by the DEA model is taken as dependent variable, and the following multiple linear regression model is constructed by taking logarithm on both sides, respectively:

$$
\ln Y=\beta_{0}+\beta_{1} \ln X_{1}+\beta_{2} \ln X_{2}+\beta_{3} \ln X_{3}+\beta_{4} \ln X_{4}+\beta_{5} \ln X_{5}+\mu \text {. }
$$

Efficient $\beta_{0}$ is the intercept term, and regression coefficient $\beta_{i}$ represents the percentage of the impact of changes in input factors on changes in ecological efficiency value, and $\mu$ is a random error term.

5.2. Tobit Model. The Tobit model, also known as sample selection model and restricted dependent variable model, refers to the value taking model when the explained variables are continuous but subject to certain restrictions, which is applicable to the cases where the explained variables have zero value and the remaining values are positive and continuous. In the estimation of the model, the potential explained variables $Y^{*}$ satisfy the basic assumptions of the classic linear model and are subject to independent normal distribution of the same variance. The basic form of the model is as follows:

$$
\begin{aligned}
Y_{t}^{*} & =a_{t}+\sum_{j=1}^{r} \beta_{j} X_{t j}+\varepsilon_{t} t=1,2, \ldots, n ; j=1,2, \ldots, r, \\
Y_{t}^{*} & = \begin{cases}Y_{t}^{*} & Y_{t}^{*} \geq 0 \\
0 & Y_{t}^{*} \leq 0\end{cases}
\end{aligned}
$$

where $X=\left(x_{1}, x_{2}, \ldots, x_{n}\right)^{\prime}$ is the vector of explanatory variables, that is, input of factors; $Y=\left(y_{1}, y_{2}, \ldots, y_{n}\right)^{\prime}$ is the vector of explanatory variables, that is, the value of eco-economic efficiency of peasant households; $\beta=\left(\beta_{1}, \beta_{2}, \ldots, \beta_{n}\right)^{\prime}$ is the parameter vector; and $\varepsilon=\left(\varepsilon_{1}, \varepsilon_{2}, \ldots, \varepsilon_{n}\right)^{\prime}$ is the residual.

5.3. Results Analysis. From Table 6, it can be seen that the OLS and Tobit results are basically the same, and the regression coefficients of the explanatory variables $X_{2}, X_{3}$, and $X_{4}$ are all negative, indicating that the increase in agricultural arable land, agricultural irrigation, and fertilizer use will have an adverse impact on the efficiency of food production. The regression coefficients of $X_{1}$ and $X_{5}$ are positive, indicating that labor input and agricultural machinery use are directly proportional to their production efficiency.

\section{Comprehensive Evaluation Model of Efficiency and Sustainability}

In the weight of environmental pollution in Table 1, the weight of fertilizer use is the largest, and in the regression analysis in Table 6, fertilizer use also has good explanatory effect. In order to express the direct connection between agricultural production efficiency and sustainability, the amount of fertilizer used is selected to connect the sustainability and production efficiency of world food production. When the fertilizer usage is reduced in a linear way [30-34], we name it as the process of increasing the proportion coefficient. When the proportion coefficient is 0 , it means to keep the original state. When the proportion coefficient is 1 , it means not to use the fertilizer. Developing countries and developed countries are selected at different stages to substitute into the environmental pollution assessment model and obtain the change relationship between EPI and proportion coefficient as shown in Figure 5; the change relationship between comprehensive technical efficiency and proportion coefficient is shown in Figure 6.

With other indicators unchanged, the impact of reducing fertilizer use on different countries is calculated. In Figure 5, the EPI of each country shows the same downward trend with the decrease in fertilizer use. In Figure 6, with the decrease in the EPI, the comprehensive technical efficiency of China is in a decreasing stage. In Germany and India, the comprehensive technical efficiency is increasing.

If Figures 5 and 6 are drawn on the same graph, the direct relationship between agricultural production efficiency and sustainability can be obtained as shown in Figure 7. This indicates that some countries have invested too much fertilizer at present, resulting in the positive expected output efficiency lower than the unexpected output efficiency. Therefore, reducing the input of fertilizer can effectively improve the production efficiency and reduce environmental pollution. 
TABLE 4: Returns to economies of scale in 2018.

\begin{tabular}{lccccccccccc}
\hline Country & CHN & USA & IND & BRA & RUS & FRA & CAN & VNM & DEU & ARG & Mean \\
\hline MALM & 1 & 1 & 0.275 & 0.278 & 0.661 & 0.059 & 0.095 & 0.111 & 0.137 & 0.066 & 0.368 \\
TECH & 1 & 1 & 0.409 & 1 & 1 & 0.31 & 1 & 0.325 & 0.642 & 1 & 0.769 \\
EFFI & 1 & 1 & 0.673 & 0.278 & 0.661 & 0.189 & 0.095 & 0.342 & 0.214 & 0.066 & 0.452 \\
Return on scale & - & - & IRS & IRS & IRS & IRS & IRS & IRS & IRS & IRS & - \\
\hline
\end{tabular}

TABle 5: Average Malmquist index.

\begin{tabular}{lcccccccccc}
\hline Country & CHN & USA & IND & BRA & RUS & FRA & CAN & VNM & DEU & ARG \\
\hline EFFCH & 0.970 & 1 & 1 & 1 & 0.928 & 1.037 & 1.017 & 1.057 & 0.875 & 1.004 \\
TECHCH & 1.003 & 0.982 & 0.972 & 0.99 & 0.993 & 0.973 & 1.006 & 0.958 & 1.001 & 0.989 \\
PECH & 1.006 & 1 & 1 & 1 & 1 & 1.007 & 1 & 1.004 & 1 & 1 \\
SECH & 0.964 & 1 & 1 & 1 & 0.928 & 1.03 & 1.017 & 1.054 & 0.875 & 1.004 \\
TFPCH & 0.973 & 0.982 & 0.972 & 0.99 & 0.922 & 1.009 & 1.023 & 1.013 & 0.876 & 0.994 \\
\hline
\end{tabular}

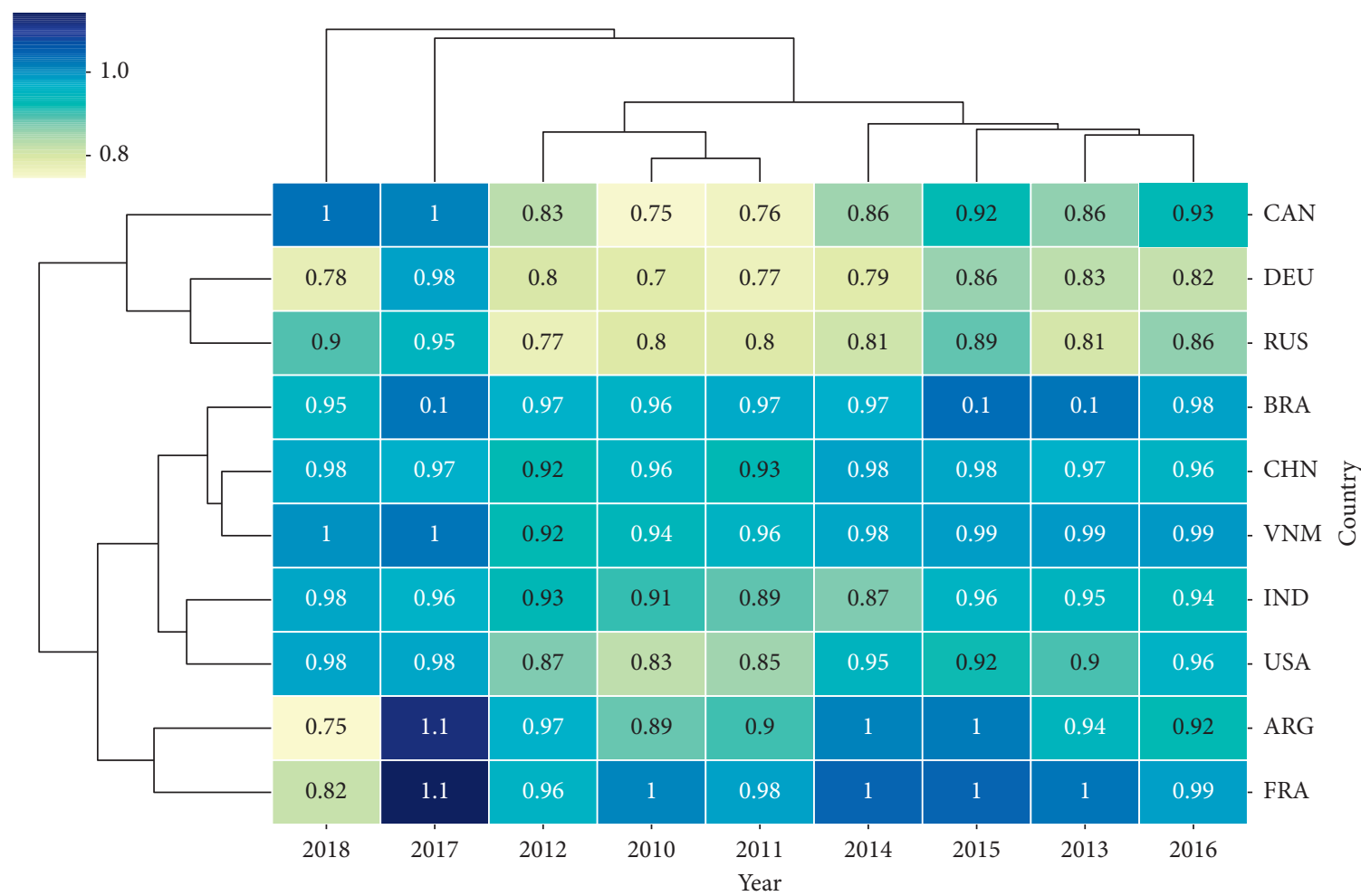

FIgURE 4: Cluster analysis of Malmquist index.

TABLE 6: Regression results of influencing factors.

\begin{tabular}{cccccccc}
\hline & Variable & $C$ & $X_{1}$ & $X_{2}$ & $X_{3}$ & $X_{4}$ \\
\hline \multirow{2}{*}{ OSL } & Coefficient & -2.8272 & 0.6859 & -0.0485 & -0.1593 & -0.2789 & 0.1784 \\
& $t$-statistic & -2.2029 & 3.2117 & -0.1692 & -0.5691 & -1.0489 & 0.6464 \\
\hline \multirow{2}{*}{ Tobit } & Coefficient & 0.3786 & 0.001 & -0.002 & -0.0044 & -0.0003 \\
& $z$-statistic & 2.408 & 2.6567 & -0.4355 & -0.486 & -0.7838 & 0.0002 \\
& & & & &
\end{tabular}




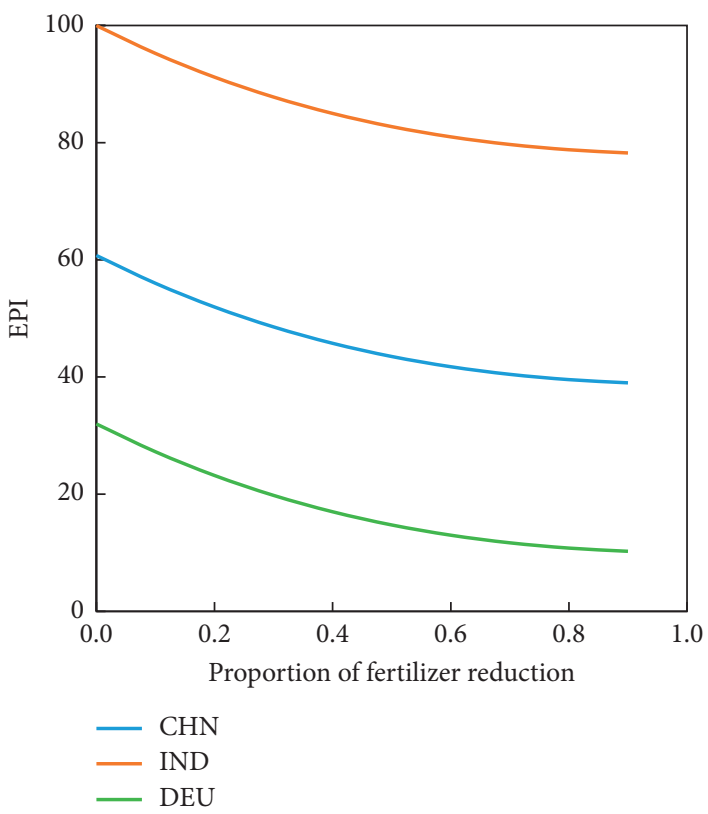

Figure 5: EPI changes.

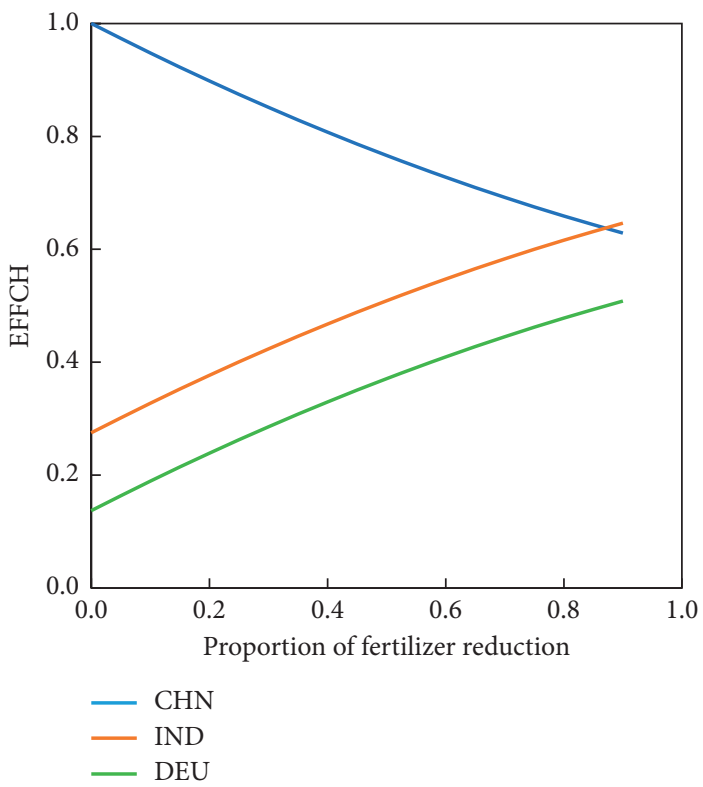

Figure 6: EFFCH changes. 


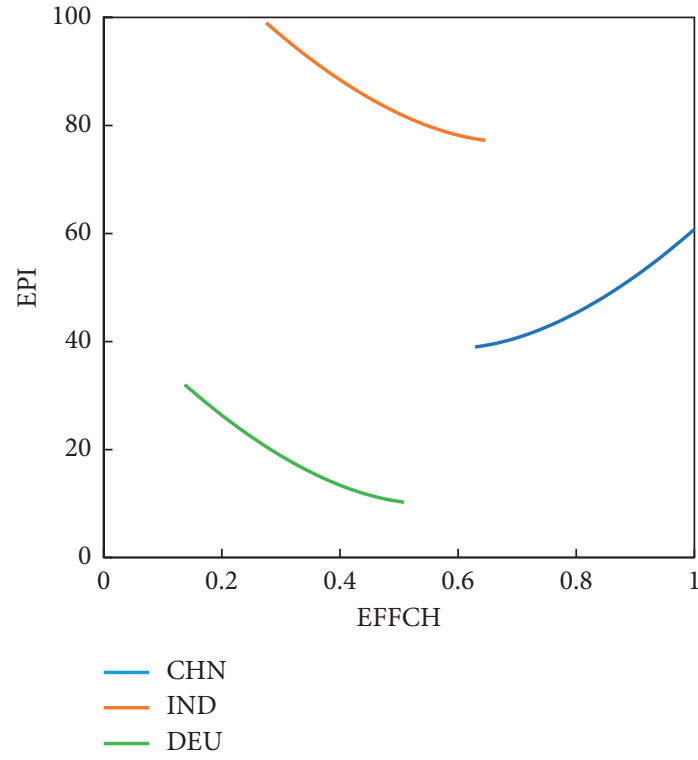

Figure 7: EFFCH-EPI.

\section{Conclusion}

(1) In this paper, 4 indicators of agricultural irrigation area, $\mathrm{CO}_{2}$ emissions, deforestation area, and fertilizer use were selected, and the environmental pollution assessment model was established by using the method of entropy weight, and the environmental pollution index was obtained. Among the 10 major agricultural producing countries, India has the highest degree of environmental pollution, and Argentina has the lowest degree.

(2) Through the establishment of the DEA model, it is found that the countries with the highest comprehensive technical efficiency are China and the United States and Vietnam has the highest rate of technological progress. The subsequent regression analysis model indicates that the increase in agricultural arable land, agricultural irrigation, and fertilizer use will have an adverse impact on the economic efficiency value of food production, and the labor input and agricultural machinery use are directly proportional to their ecological economic efficiency value.

(3) The OSL and Tobit models were used to conduct regression analysis on the factors affecting the production efficiency, and the results showed that the increase in agricultural arable land, agricultural irrigation, and fertilizer use would have an adverse impact on the food production efficiency. The input of labor force and the use of agricultural machinery are directly proportional to their production efficiency.

(4) Combining the environmental pollution index with the comprehensive technical efficiency, the relationship between the two has been obtained through the control of fertilizer use. Some countries have invested excessive fertilizer in production, resulting in the positive expected output efficiency lower than the unexpected output efficiency. Reducing the input of fertilizer can effectively improve the production efficiency and reduce environmental pollution.

The research of this paper also has some deficiencies as follows:

(1) Due to the lack of data, the latest data can only be researched into 2018, and the changes in the last two years have not been considered.

(2) In this paper, only 10 countries are selected to represent the global agricultural production system, and the environmental pollution status of some countries with characteristic crops is not considered, which may be different from the main agricultural producing countries.

In conclusion, our research results can provide a theoretical basis for evaluating the efficiency of agricultural production and the health of environmental pollution system in a country and contribute to the reform of agricultural development so as to promote environmental protection and sustainable development of agriculture.

\section{Data Availability}

The data used to support the findings of this study are included within the article.

\section{Conflicts of Interest}

The authors declare that there are no conflicts of interest regarding the publication of this paper.

\section{Acknowledgments}

This work was supported by the General Project of Philosophy and Social Science Planning of Anhui Province: Research on Government R\&D Subsidies Promoting Green Innovation Efficiency of Anhui High-Tech Industries (no. AHSKY2019D085); Anhui University of Finance and Economics School-Level Teaching and Research Fund Project (no. acjyyb2020011); Key Projects of Support Program for Outstanding Young Talents in Anhui Province Colleges and Universities (no. gxyq2018119); Key Project Funds from Anhui Education Ministry (no. 2019rcsfjd089); and Student Scientific Research Fund Project of School of Economics, Anhui University of Finance and Economics (no. ACJJXYZD2002).

\section{References}

[1] F. Galli, A. Cavicchi, and G. Brunori, "Food waste reduction and food poverty alleviation: a system dynamics conceptual model," Agriculture and Human Values, vol. 36, no. 2, pp. 289-300, 2019.

[2] G. O'Kane, "What is the real cost of our food? Implications for the environment, society and public health nutrition," Public Health Nutrition, vol. 15, no. 2, pp. 268-276, 2012. 
[3] T. Li, T. Baležentis, L. Cao, J. Zhu, D. Štreimikienè, and R. Melnikienè, “Technical change directions of China's grain production: application of the bias-corrected malmquist indices," Technological and Economic Development of Economy, vol. 24, no. 5, pp. 2065-2082, 2018.

[4] D. Abler, "Economic evaluation of agricultural pollution control options for China," Journal of Integrative Agriculture, vol. 14, no. 6, pp. 1045-1056, 2015.

[5] J. S. Zhang, X. Y. Yan, and X. Z. Hu, "Calculation of the agricultural total factor productivity and its influencing factors in Chongqing of China," European Journal of Agronomy, vol. 28, no. 1, pp. 1810-1812, 2017.

[6] S. U. K. Rohmer, J. C. Gerdessen, and G. D. H. Claassen, "Sustainable supply chain design in the food system with dietary considerations: a multi-objective analysis," European Journal of Operational Research, vol. 273, no. 3, pp. 11491164, 2019.

[7] W. N. Chang, H. P. Zhou, and Y. Gao, "Balance between planting and breeding-discussion on the mode of reducing agricultural pollution," Journal of Agro-Environment Science, vol. 32, no. 11, pp. 2118-2124, 2013.

[8] P. Yan and L. Z. Zhu, "Agricultural pollution control in China: defects in environmental regulation and adverse selection of stakeholders," Issues in Agricultural Economy, vol. 36, no. 11, pp. 73-80, 2015.

[9] W. N. Chang and H. P. Zhou, "Preliminary construction of agricultural pollution reduction index system," Journal of Ecology and Rural Environment, vol. 28, no. 4, pp. 456-461, 2012.

[10] X. F. Li, J. Z. Zhu, X. J. Gu, and J. J. Zhu, “The present situation of the pollution of the non-point source of agriculture and the progress of its control," China Population, Resources and Environment, vol. 20, no. 4, pp. 81-84, 2010.

[11] Q. Yang and H. J. Liu, "The regional difference and influence factors of the efficiency of the rural water resources in China under the influence of the pollution," The Journal of Quantitative \& Technical Economics, vol. 32, no. 1, pp. 114-128, 2015.

[12] J. L. Zhu, Q. J. Yang, and G. Y. Wang, "Based on LCA, an assessment of the development of low-carbon agriculture in Anhui province and an analysis of the impact factors," Henan Agricultural Sciences, vol. 45, no. 9, pp. 64-68, 2016.

[13] F. L. Zhong, X. Yang, and A. J. Guo, "Study on the eco economic efficiency of oasis agriculture in the arid area based on the combination of LCA and DEA-Taking the planting of corn in Zhangye city as an example," Ecological Economy, vol. 33, no. 11, pp. 122-127, 2017.

[14] L. Lei and X. X. Tuo, "Evaluation of comprehensive innovation and development ability of modern agricultural science and technology park in Shaanxi based on supply side structural reform-a model based on the combination of the method of entropy weight and TOPSIS," Science and Technology Management Research, vol. 39, no. 3, pp. 114-120, 2019.

[15] M. Li, S. F. Li, and Y. H. Ouyang, "The evaluation and analysis of modern agricultural development level of Zhuolu County based on the method of entropy weight," Journal of China Agricultural University, vol. 19, no. 5, pp. 236-243, 2014.

[16] C. Zhang, Z. M. Li, X. X. Dong, and C. Y. Peng, “An analysis of the agricultural development level of BRICs countries-a comparative study based on the method of entry-level weight and the method of coefficient of variation," Science \& Technology and Economy, vol. 27, no. 6, pp. 42-46, 2014.
[17] X. L. Tang, J. Q. Wang, B. Zhang, and L. X. Zhang, “Application of the DEA on the performance evaluation of the agricultural support policy in China," Agricultural EconomicsZemedelska Ekonomika, vol. 63, no. 11, pp. 510-523, 2017.

[18] Q. X. Lu and X. H. Meng, "Research on agricultural production efficiency of Jiangsu Province based on 3 stage DEA model," Northeast Agricultural Science, vol. 46, no. 1, pp. 94-99, 2021.

[19] H. F. Wang, Y. S. Shi, and C. Y. Yi, "Land use efficiency and its changes of Shanghai development zone based on DEA model and Malmquist productivity index," Geographical Research, vol. 33, no. 9, pp. 1636-1646, 2014.

[20] L. Pang, "Analysis on regional differences and influencing factors of agricultural carbon emissions in China," Journal of Arid Land Resources and Environment, vol. 28, no. 12, pp. 1-7, 2014.

[21] Y. T. Yao and W. M. Chen, "The present situation of greenhouse gas and the development mode of low-carbon agriculture," Science \& Technology Progress and Policy, vol. 27, no. 22, pp. 48-51, 2010.

[22] L. P. Zhang, J. Xia, and Z. F. Hu, "An analysis of the situation and safety of water resources in China," Resources and Environment in the Yangtze Basin, vol. 18, no. 2, pp. 116-120, 2009.

[23] F. Y. Xu, Y. C. Gai, Z. M. Xu, and W. Z. Wang, "Study on the assessment method of water productivity of crops," Journal of Glaciology and Geocryology, vol. 35, no. 1, pp. 156-163, 2013.

[24] M. Wei, "System and living world in climate change governance: a case study of peat swamp forest destruction in Indonesia under palm oil development," Communication of Dialectics of Nature, vol. 42, no. 9, pp. 106-111, 2020.

[25] Z. Chen, Y. Y. Xu, Z. J. Zhai, and S. Huang, "Analysis of agricultural production efficiency of Henan Province based on SBM-DEA model," Journal of Henan Agricultural University, vol. 53, no. 4, pp. 647-652, 2019.

[26] J. Li and D. R. Cheng, "A study on the efficiency of the environment in China based on DEA-SBM model," Journal of Hefei University of Technology (Natural Science Edition), vol. 32, no. 8, pp. 1208-1211, 2009.

[27] X. H. Chen, G. D. Yi, and X. Liu, "Based on the three stage SBM-DEA model, a study on the efficiency of the Chinese region's carbon discharge," Operations Research and Management Science, vol. 26, no. 3, pp. 115-122, 2017.

[28] Y. Yang and S. B. Jiang, "Evaluation of agricultural irrigation water use efficiency in China based on DEA and malmquist index," Ecological Economy, vol. 32, no. 5, pp. 147-151, 2016.

[29] W. E. Jiao, G. C. Guo, and Y. S. Chen, "Research on the impact of agricultural land transfer on agricultural production efficiency-based on the analysis of DEA-Tobit model," Resources Science, vol. 37, no. 9, pp. 1816-1824, 2015.

[30] J. B. Liu, J. Zhao, and J. Min, "On the Hosoya index of graphs formed by a fractal graph," Fractals-Complex Geometry Patterns and Scaling in Nature and Society, vol. 27, no. 8, pp. 19-35, 2019.

[31] X.-B. Liu, Y.-J. Zhang, W.-K. Cui, L.-T. Wang, and J.-M. Zhu, "Development assessment of higher education system based on TOPSIS-entropy, hopfield neural network, and cobweb model," Complexity, vol. 2021, Article ID 5520030, 11 pages, 2021.

[32] J.-M. Zhu, Y. Chen, and S. Zhang, "Analysis of the impact of climate change on national vulnerability based on fuzzy comprehensive evaluation," Discrete Dynamics in Nature and Society, vol. 2020, Article ID 3527540, 10 pages, 2020. 
[33] F. Xu, Y.-A. Du, H. Chen, and J.-M. Zhu, "Prediction of fish migration caused by ocean warming based on SARIMA model," Complexity, vol. 2021, Article ID 5553935, 9 pages, 2021.

[34] R. Xie, R. Liu, X.-B. Liu, and J.-M. Zhu, "Evaluation of SMEs' credit decision based on support vector machine-logistics regression," Journal of Mathematics, vol. 2021, Article ID 5541436, 10 pages, 2021. 